\title{
The Discovery of Critical Illness Polyneuropathy: A Memoir
}

\author{
Charles F. Bolton
}

Can. J. Neurol. Sci. 2010; 37: 431-438

Presented in part as an invited talk at the University of Brescia, Italy, 2007 ${ }^{1}$, and as an I-Pod interview for the American Association of Neuromuscular and Electrodiagnostic Medicine, 2008.

Critical illness has come to mean sepsis and multiple organ failure. Sepsis, which is due to invading organisms or severe trauma, provokes a systemic inflammatory response syndrome leading to septic shock and organ dysfunction. Sepsis occurs in two percent of hospitalized patients and utilizes 25 percent of Intensive Care Unit (ICU) beds. Mortality rates exceed 20 percent. Sepsis is evident in most patients who, while receiving mechanical ventilation and intravascular lines, are in the ICU for more than one week.

It is now known that the nervous system, like other organs, is afflicted in these critically ill patients. Septic encephalopathy causes stupor or coma. Critical illness polyneuropathy, myopathy, or a combination of both, causes difficulty weaning from mechanical ventilation and limb weakness. These nervous system complications occur in up to 70 percent of critically ill patients. ${ }^{2}$ All are reversible if the critical illness can be successfully treated, possible in at least half the cases.

As workers in the ICUs struggle to overcome these widespread effects, the nervous system complications are overlooked or misdiagnosed. Stupor may be attributed to sedation, weaning difficulties to diaphragmatic fatigue, and limb weakness to catabolic myopathy. With successful weaning the patient is discharged to a general ward. Here the patient may still show mental confusion. There is difficulty dressing, eating, rising from a bed or toilet seat, standing, and walking. Shortness of breath and fatigue is evident. Unless further investigated, the nature of these symptoms remains unexplained, and a puzzle to the patient, family, and caregiver.

Fortunately, intensivists are now tackling the problem. Intensive Care Unit patients are being taken off sedation at regular intervals to test their level of consciousness so that the level of sedation can be more accurately determined. ${ }^{3}$ At this time, limb strength can be assessed. If weakness increases electrophysiological, and in some instances, muscle biopsy procedures are performed. ${ }^{4}$ The presence of critical illness polyneuropathy, critical illness myopathy, or both can be accurately identified, greatly aiding long-term management and attempts at prognosis.

Thirty years ago, when I and my colleagues in the Department of Clinical Neurological Sciences at Victoria Hospital, London, Ontario, Canada, began to consult on neurological problems in the ICU the above conditions were little known. A series of investigations were conducted that did

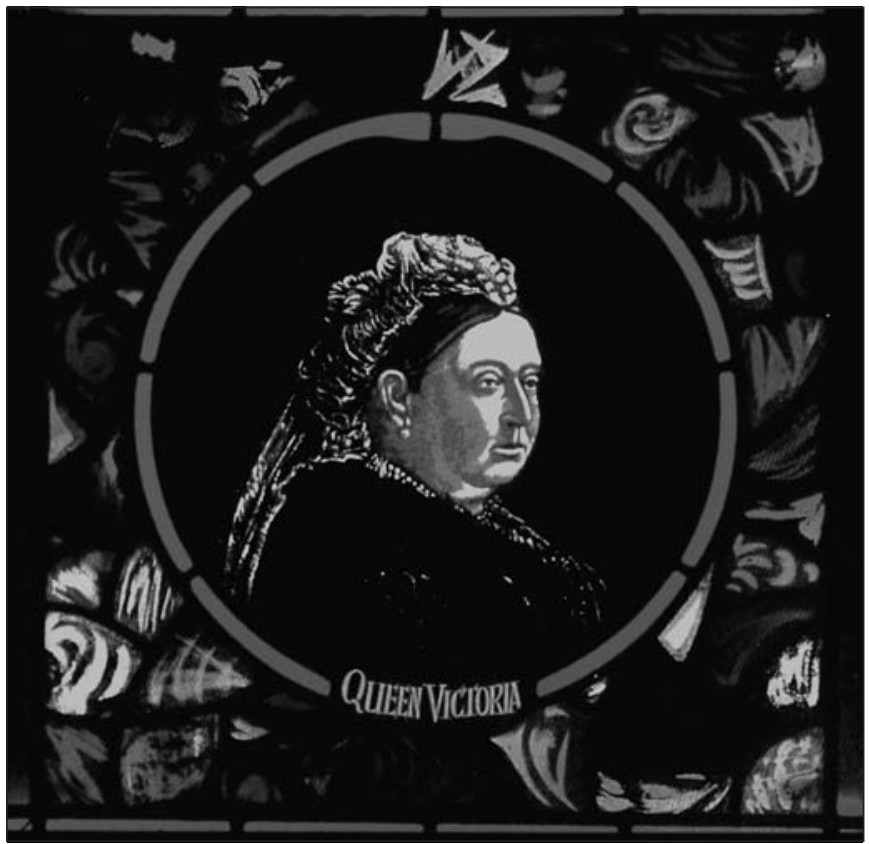

Figure 1: The portrait of Queen Victoria which hangs in the entrance to Victoria Hospital, London, Ontario, Canada.

much to illuminate their nature and bring them to the attention of the medical community.

The following is a personal account, a memoir, of these investigations.

\section{Critical Illness Polyneuropathy}

In the 1970s, Victoria Hospital, University of Western Ontario, London, was one of Canada's oldest teaching hospitals. It had been named as part of the Queen Victoria jubilee celebrations in 1897 . The portrait of the good queen still hangs

From the Department of Medicine, Queen's University, Etherington Hall, Kingston, Ontario, Canada.

Received October 23, 2009. Final Revisions Submitted January 10, 2010. Correspondence to: Charles Bolton, Department of Medicine, Queen's University, Etherington Hall, 94 Stuart Street, Kingston, Ontario, K7L 3N6, Canada. 


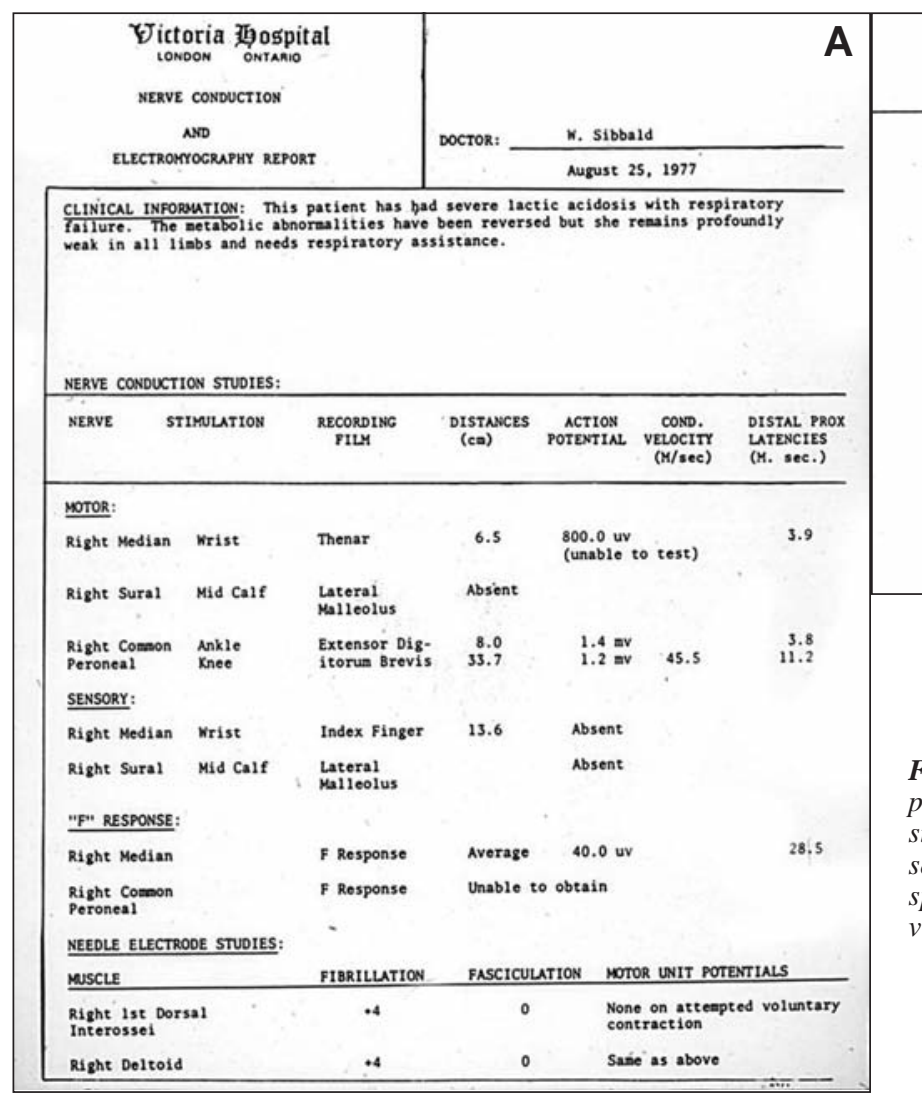

in the entrance (Figure 1). The hospital had a busy Emergency department and a crowded operating room schedule. The large 30-bed general and medical ICU was quickly developing an international reputation, notably for its investigation of sepsis and septic shock.

In 1977, while I was Chief of Clinical Neurological Sciences at Victoria Hospital and Director of the EMG laboratory, William Sibbald, Director of the ICU, asked me to investigate a 56-yearold woman. Sibbald had trained for three months in our neurology service and he and his staff readily asked for neurological consultations. The woman had been in the ICU for three weeks but could not be weaned from the ventilator. I knew an EMG would be necessary and so Sibbald arranged for the patient to be transferred to our EMG laboratory since we did not have a portable EMG system at that time. The patient was attached to a ventilator and was receiving intravascular lines. Intensive Care Unit nurses were in constant attendance during this time. In the laboratory I obtained the history, mainly from reviewing the hospital chart and speaking to the ICU nurses, but briefly questioning the patient, who answered with nods and head shakes. At this point the patient was alert although had previously been confused. A reasonably complete neurological assessment was achieved.

She had been admitted to the ICU with severe pneumonia due to Staphococcal aureus and Klebsciella pneumonia, complicated by lactic acidosis, dehydration, and transient renal failure. She had required endotracheal intubation, mechanical ventilation, and management in the ICU. Cephalolithin sodium and gentamycin had been prescribed.

I noted neck, chest wall, abdomen, and limb muscles were very weak. Tendon reflexes were absent. Position sense and vibration sense were distally impaired, but pinprick was preserved. The electrophysiological studies indicated severe axonal degeneration of motor and sensory fibers (Figure 2).

Possible causes of an axonal polyneuropathy were negative: cerebrospinal fluid examination, blood levels of antibiotics, urinary porphyrins, acute and chronic convalescent serum for Influenza A \& B, adenovirus, psyticosis, mycoplasma pneumonia, respiratory syncitial virus, mumps, herpes simplex, and varicella viruses, tissue culture and animal anoculation of the cerebrospinal fluid, serum thyroxine, phosphate and magnesium, creatine phosphokinase, and B12. The serum albumin and blood lymphocyte counts were reduced.

She was treated with total parental nutrition and gradual recovery occurred. She left the hospital in a wheelchair at four and a half months. At six months, strength was improved. Tendon reflexes were still absent but vibration sense and position sense were now normal. Repeat EMG studies confirmed the improvement (Figure 3). At two year follow-up, she could walk independently but had residual signs of polyneuropathy.

During the next four years, three more patients with similar findings were observed. The fifth patient was a 29 -year-old male 
who presented with severe head trauma. At 14 days his limbs were first noted to be flaccid and immobile. Persisting infection prevented transfer to the EMG laboratory and a neurological consultation was not performed. At three months, he died of a cardiac arrest following an emergency cholecystectomy.

This fifth patient was presented at Victoria Hospital Neurological Sciences Grand Rounds. Comprehensive autopsy studies of both the central and peripheral nervous system were performed by Joseph Gilbert, Director of Neuropathology. Multiple samples of nerve and muscle, trunk, proximal and distal limbs, were examined. These studies revealed a severe, distal, axonal degeneration of motor and sensory fibers with resulting denervation atrophy of muscle. The distal nature of neuropathy was emphasized by the normal appearance of the spinal cord (except for chromatolysis of anterior horn cells), and of motor and sensory nerve roots. It is likely autopsies of ICU patients in other institutions had failed to identify critical illness polyneuropathy because only brain, spinal cord and nerve roots were examined, not the distal nerves and muscles.

I immediately recalled the four earlier patients; two of these had also died and had come to autopsy revealing similar findings. Angelika Hahn, my colleague in neuromuscular disease, and a former research fellow, and I had puzzled over the nature of these polyneuropathies. All had in common severe sepsis and multiple organ failure, termed critical illness by intensivists.
We presented our findings at several national and international meetings where there was little interest. No one, to my knowledge, attended some of the poster sessions. Neuromuscular experts thought these were simply examples of Guillain-Barré syndrome. The editor of The Annals of Internal Medicine rejected our first paper documenting these five patients, wondering why the cerebrospinal fluid protein was so low in patients who obviously had Guillain-Barré syndrome? He wondered if our laboratory was in error in testing for protein. Finally Dr. David Marsden, editor of the Journal of Neurology, Neurosurgery and Psychiatry, accepted the paper and it was published in $1984 . .^{5}$

We began to look for similar patients in the ICU. We soon observed 15 . These were compared to 16 with Guillain-Barré syndrome observed during the same period. Guillain-Barré syndrome was often preceded by a minor infection or inoculation with a latent period of days or weeks before its onset. "Critically ill polyneuropathy" as we called it at that time, developed during the course of the critical illness. Guillain-Barré syndrome was a demylinating polyneuropathy while critically ill polyneuropathy was of a primarily axonal nature. ${ }^{6}$

However, during this period we did observe five patients who had an unusually severe axonal polyneuropathy, but who otherwise had all the features of Guillain-Barré syndrome. Tom Feasby was the lead author of the paper reporting these patients,

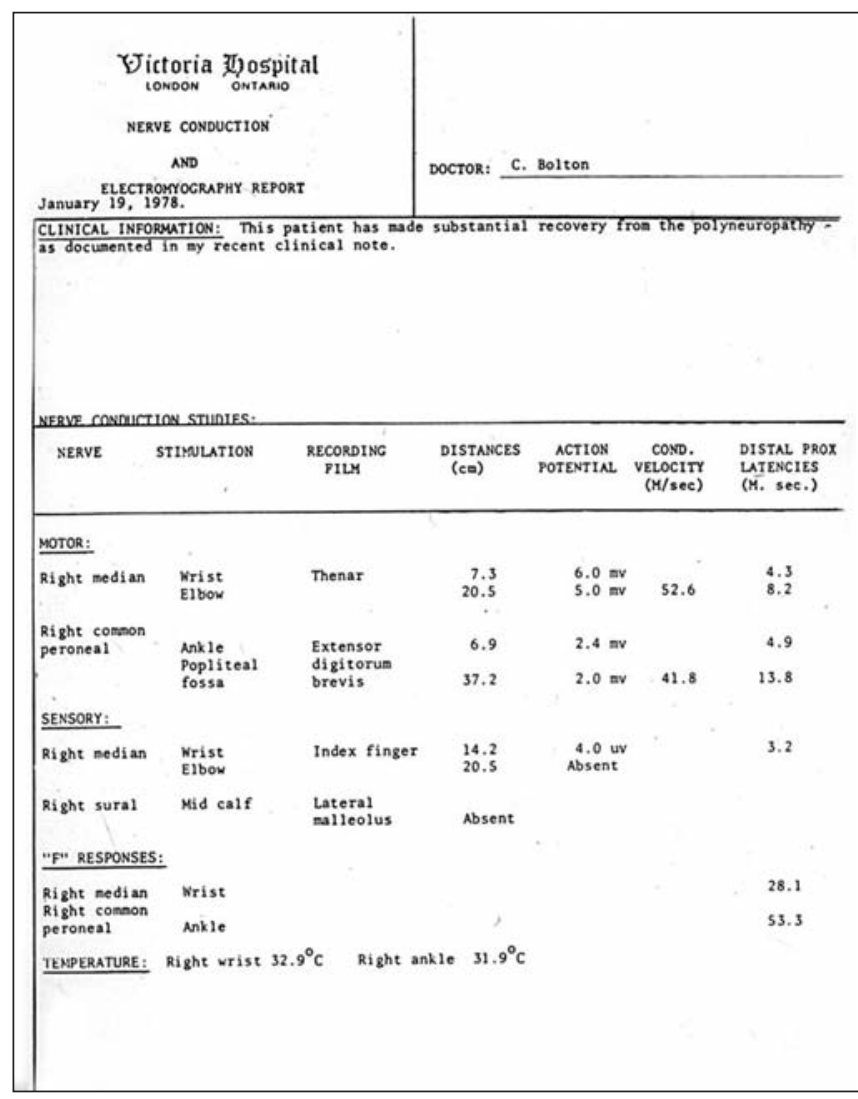

NEELDE ELECTRODE STUCIES:

MUSCLE FIBRILLATION FASCICULATION MOTOR UNIT POTENTIALS

Right quadriceps $\quad * 1 \quad 0 \quad \begin{aligned} & \text { Four polyphasic units; one } \\ & \text { nascent unit. }\end{aligned}$

Right medial gastrocnearius $\quad+1 \quad 0 \quad$ Three polyphasic units, one

Right first dorsal interosseous $0 \quad 0 \quad$ Six moderately polyphasic units (somewhat poor
recruitment)

Right deltoid occasional S1ightly decreased number: positive wave $\quad 0 \quad \begin{aligned} & \text { reaaining ones moderat } \\ & \text { large and polyphasic. }\end{aligned}$

COMMENT: The right median and common peroneal motor conduction velocities are noraal. Motor and sensory compound action potentials are still somewhat reduced or absent. but there has been considerable improvenent in comparison to testing done six months ago. Needle electrode study also shows considerable reinnervation of muscle - in comparision to previous testing. Thus, there has been a substantial improvement in
motor and sensory polyneuropathy.

$\mathrm{CFB} / \mathrm{jm}$ C. F. Bolton, M.D.,F.R.C.P. (C).

Figure 3: At six months the amplitudes of compound muscle action potentials were normal, a low amplitude sensory potential was now recordable from the median nerve and needle EMG study showed considerable re-innervation of muscle. 


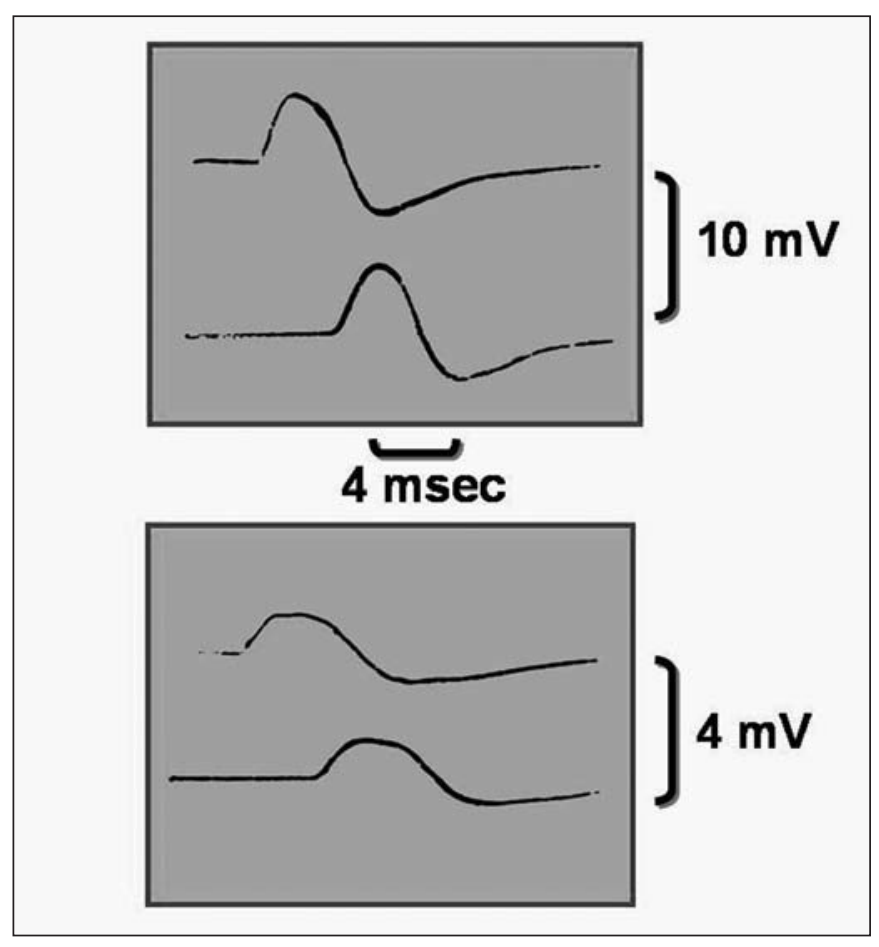

Figure 4: Evidence of neuromuscular dysfunction in the early stages of sepsis, at its onset, upper two traces, and three weeks later, lower two traces. Note the marked decline in amplitude, but also the increase in duration, to a similar degree on both proximal and distal stimulation of the median nerve, recording from the thenar muscle. These changes suggested primary dysfunction of the muscle fiber membrane. ${ }^{18}$

published in the journal Brain. ${ }^{7}$ The condition has since been recognized as acute motor and sensory axonal neuropathy (AMSAN), a variant of Guillain-Barré syndrome.

Electrophysiological studies were essential in identifying these polyneuropathies since clinical signs in half the cases were equivocal. ${ }^{8}$ By 1983, 19 patients had been collected. Douglas Zochodne, neuromuscular research fellow, agreed to review the extensive clinical records.

The electrophysiological features again confirmed the primary axonal degeneration of motor and sensory fibers. Comprehensive morphological studies at autopsy in nine patients, and superficial and deep peroneal, and sural nerve biopsy in two patients mirrored the electrophysiological features. To detect the earliest changes in nerve, the techniques of semithin sections and teased fiber preparations ${ }^{9}$ were utilized. There was denervation atrophy of type I and type II fibers. Necrosis and ultrastructural changes in muscle in four patients suggested primary involvement of muscle. Phrenic nerve conduction studies, and morphological studies of phernic nerves and diaphragm, explained the respiratory insufficiency and difficulty in weaning from mechanical ventilation. ${ }^{10}$

P.K. Thomas, editor of Brain, readily accepted the manuscript but indicated instead of "Critically Ill Polyneuropathy" the correct term should be "Critical Illness Polyneuropathy". I sent
Thomas' letter to the heads of the Departments of English and Journalism at the University of Western Ontario. Both agreed with Thomas. I wrote Thomas, "P.K., I should know better than to correct an Englishman about his own language". Thomas responded, "Yes Charlie, but I am Welsh, not English" (Ouch!!).

Before our research of the 19 cases began, I had met with George Wells, statistician at the University of Western Ontario. We assembled a protocol for the chart review, but one that could also be applied to a prospective study that we were planning. Norbert Witt, neuromuscular fellow, carefully conducted this prospective study. The results were published in the journal Chest in 1991. ${ }^{11}$

We took into account certain important factors in the analysis of these 49 patients. In the past, interpretation of electrophysiological studies had centered on measurements of conduction velocity, but in primary axonal degeneration these are only mildly affected. The main affect is on the amplitudes of the compound muscle and sensory nerve action potentials. This was apparent to me in my earlier investigations of uremic neuropathy. ${ }^{12}$ More accurate electrophysiological methods needed to be developed to identify abnormality in an individual

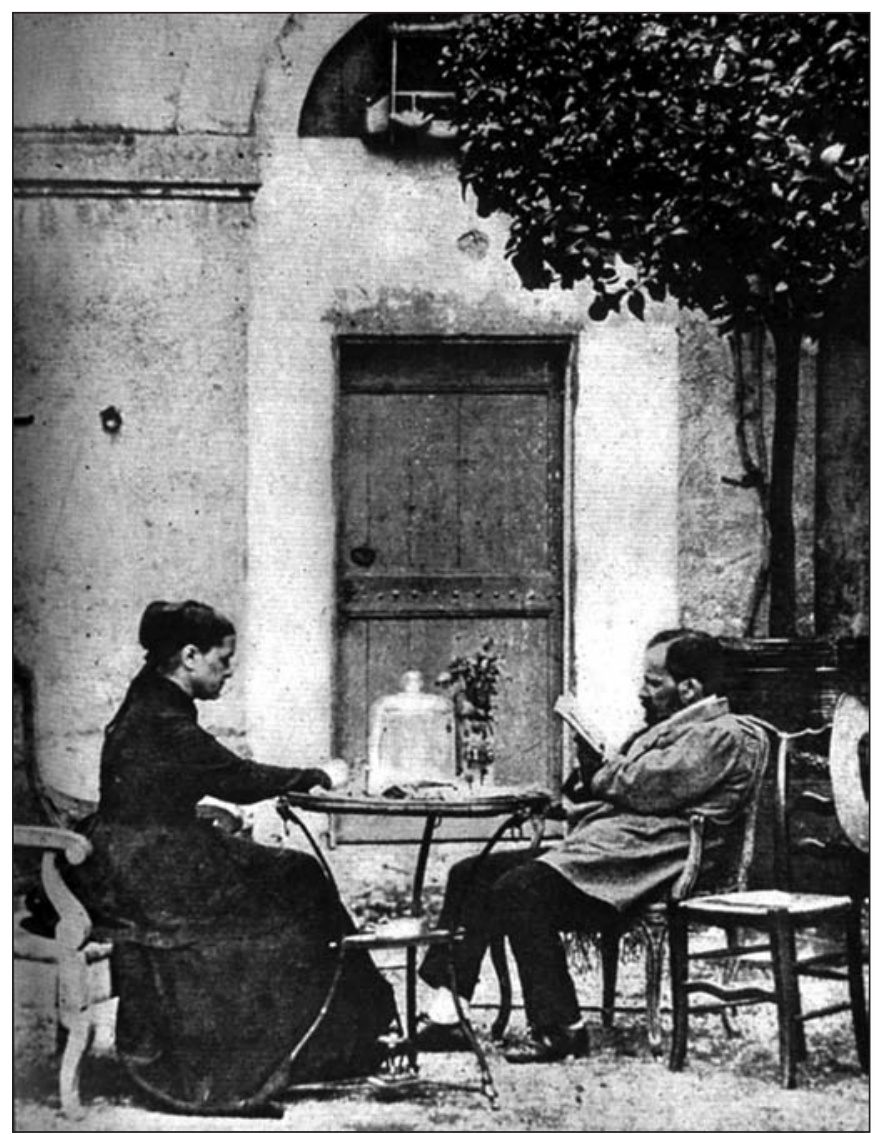

Figure 5: Pasteur with his wife who helped him in his research. ${ }^{27}$ 


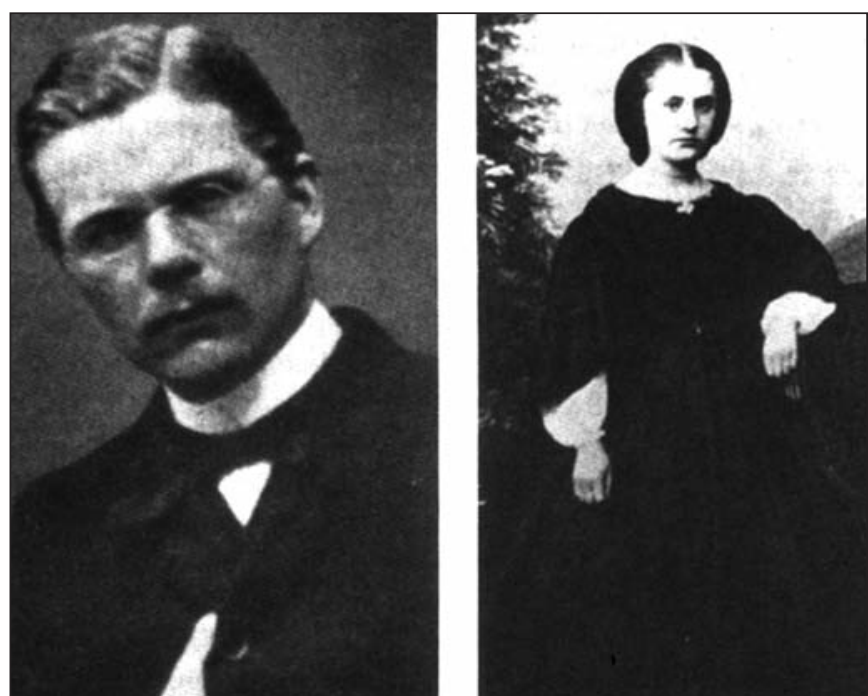

Figure 6: Koch with his wife, also an assistant in his research. ${ }^{28}$

patient and significant changes in follow-up. The fact that advancing age reduced these amplitudes was well known. However our research showed that reduced limb temperature ${ }^{13}$ and smaller limb girth in females ${ }^{14}$ increased these amplitudes. These factors were accommodated in the statistical analysis. We also used a composite score combining all electrophysiological results from each patient into a value, a percentage of normal, which we termed "peripheral nerve function index". This index was used in the statistical analysis to determine which of a wide variety of factors could have been responsible for the reduced peripheral nerve function. Only three proved statistically significant: time in the ICU, reduced serum albumin and elevated blood sugar. All were well-known markers of sepsis. The results of our studies provided no traditional cause for a primary axonal degeneration such as B vitamin deficiencies, antibiotic toxicity, etc. ${ }^{11}$

These studies further confirmed our suspicion that sepsis was at the basis of the nervous system complication. Here was a condition, critical illness, with widespread, potentially devastating affects. Could the entire nervous system be affected with the other organs?

We had evidence of the affects on the peripheral nervous system, but what about the central nervous system? Again the evidence was strong. All patients with critical illness polyneuropathy had acquired an encephalopathy of varying severities before their polyneuropathy became evident. Septic encephalopathy had been recognized and there had been animal studies to try and determine its nature. However, there had been no documentation of the clinical, electrophysiological and morphological features in humans. These were to be disclosed by Jackson, resident in neurology ${ }^{15}$, and Bryan Young ${ }^{16}$, my colleague and Director of the Electroencephalography laboratory. Young had then, and continues to have a great interest in encephalopathies in the ICU.

Sibbald asked me to present our findings at a three-day conference in Florida attended by North American experts in sepsis and septic shock. ${ }^{17}$ Our contention that septic encephalopathy and critical illness polyneuropathy were due to sepsis and septic shock were readily accepted by the intensivists, and I gained, at this meeting, new insights into possible basic mechanisms.

Could muscle as well as brain and peripheral nerve also be affected? Until our observations, muscle weakness in the ICU had been attributed to a catabolic myopathy, and difficulty in weaning, to diaphragmatic fatigue. While muscle weakness could readily be explained by the polyneuropathy, I had observed myopathic appearing units on needle EMG and Gilbert, Hahn and Zochodne ${ }^{10}$ had observed necrosis and ultra-structural changes of muscle suggesting features of a primary myopathy. Moreover on analyzing images of the compound muscle action potentials, I had observed that while the amplitude dropped in the early stages of sepsis, there was also an increase in the duration $^{18}$, (Figure 4). This distinctive appearance could not be explained by denervation, but was due to primary dysfunction of the muscle fiber membrane.

Zochodne pursued the muscle problem. P31 nuclear magnetic resonance spectroscopy revealed in patients who were not septic, but had generalized denervation of forearm muscles due to disuse atrophy, a marked depletion of bioenergetic reserves. ${ }^{19}$ But there was an even greater depletion in two patients who had had a severe critical illness polyneuropathy and myopathy. ${ }^{20}$
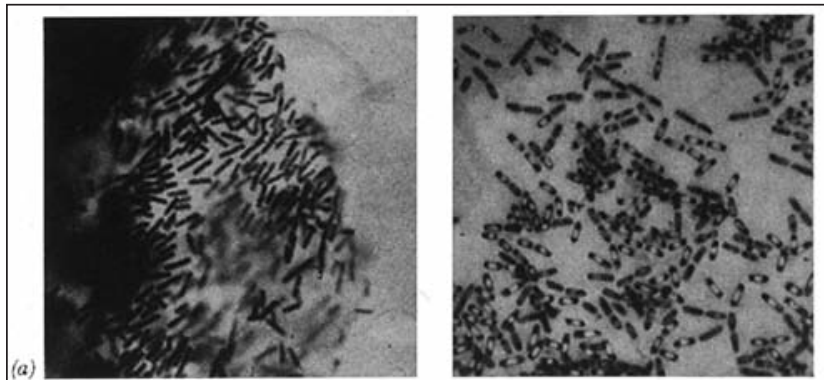

(b)
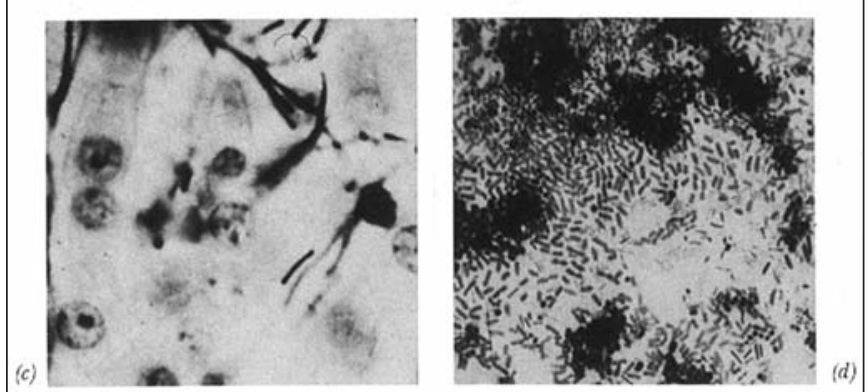

Figure 7: Koch utilized highly sophisticated microscopic and photographic techniques to observe "the germs". The results were remarkable, even by present standards. ${ }^{28}$ 
Thus bioenergetic failure might also explain the reduced amplitude and increased duration of the compound muscle action potentials.

In the 1970s, about the same time we were observing our cases of critical illness polyneuropathy, others were observing myopathies of various designations, most frequently called "acute quadriplegic myopathy". ${ }^{21}$ Initially these cases were not clearly linked to critical illness. However, Op de Coul, a Dutch neurologist and an early pioneer of neurocritical care, suggested nerve and muscle were together affected, a "critical illness polyneuromyopathy". ${ }^{22}$ More recent studies have solidified the relation of the myopathy to sepsis. Lacomis and colleagues have defined the entity of critical illness myopathy. ${ }^{23}$ Electrophyiologically it is often characterized by inexcitably muscle membranes on direct muscle stimulation, first identified by Rich and colleagues in Philadelphia. ${ }^{24}$ It has a variety of morphological features, notably myosin deficiency, less frequently muscle necrosis. However, in a few cases muscle necrosis may be quite severe, a condition indentified by Zochodne and colleagues at Queen's University, Kingston, Ontario, Canada, as "acute necrotizing myopathy of intensive care" ${ }^{25}$ Finally, critical illness polyneuropathy and myopathy often occur together as reported by Latronico and colleagues in Italy. ${ }^{26}$ In my view, critical illness myopathy is more likely to occur in critically ill patients who have received neuromuscular blocking agents and steroids, patients with severe asthma or patients in the post organ transplant state. Critical illness polyneuropathy was more common than critical illness myopathy in our ICU, whose patients were not treated after organ transplantation, and where neuromuscular blocking agents and steroids were rarely used.

\section{The Phenomenon of Sepsis}

When I first observed patients with critical illness polyneuropathy and we were still puzzling about the underlying etiology, I would often hear the word 'sepsis' mentioned in the ICU. I asked intensivists, "What is this thing called sepsis?" At that time, while there had been extensive investigations, which continue to the present day, definitions and underlying mechanisms were uncertain.

Sepsis originally meant putrefaction, or decomposition of organic matter. Through culture techniques, Pasteur (1822-1895) (Figure 5) showed the decomposition was due to microorganisms, supporting the germ theory of infection. ${ }^{27}$ It was Robert Koch (1843-1910) (Figure 6) who first saw these germs under the microscope (Figure 7). Virchow, the father of cellular pathology, and a highly influential scientist was dismissive, "whole business seemed quite improbable". Koch persisted and went on to great fame. ${ }^{28}$

In his famous textbook, The Principles and Practices of Medicine, published in 1892, Osler (1849-1919) wrote extensively on the effects of sepsis on the human body, including effects on the peripheral nervous system, where he observed "a rapid loss of flesh" 29 (Figure 8). For many years this rapid loss of flesh was attributed to a catabolic myopathy, and respiratory muscle weakness to diaphragmatic fatigue. Before our observations were first published in 1983, several reports described patients who were remarkably similar to our own. Erbsloh $^{30}$ in 1955 observed a polyneuropathy following anoxic

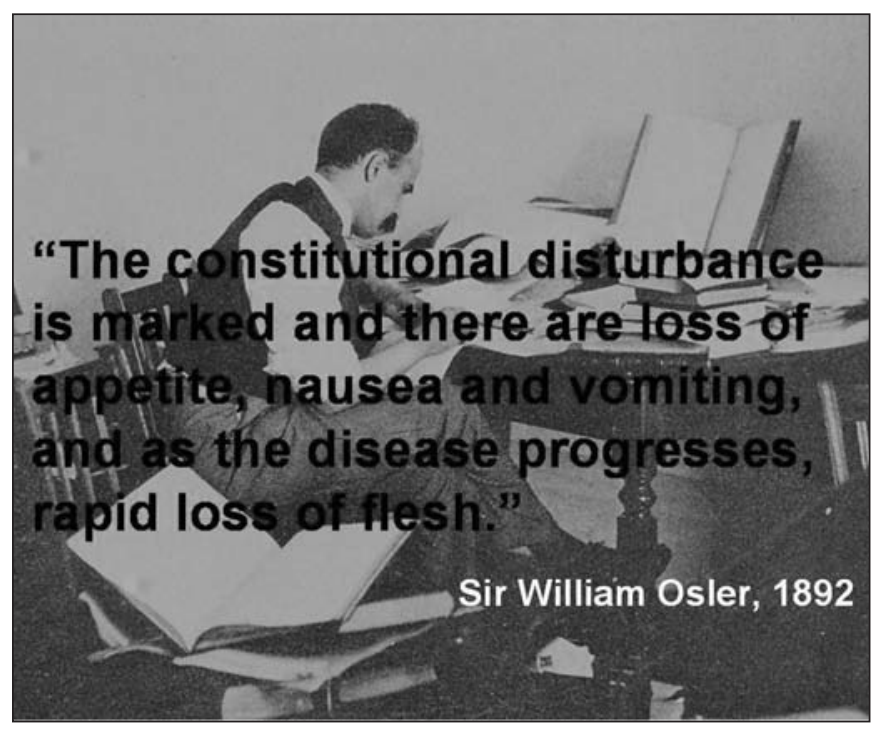

Figure 8: Sir William Osler's comments on the effects of prolonged sepsis on muscle. ${ }^{29}$

coma after shock or cardiac arrest. In 1961, Mertens ${ }^{31}$ described "coma polyneuropathies" in patients who had circulatory shock associated with acute intoxication and severe metabolic crisis, seemingly due to metabolic and ischemic lesions of the peripheral nervous system. In 1971 Henderson et al ${ }^{32}$ described a polyneuropathy in patients with burns. Four septic patients developed a severe polyneuropathy in 1977, which Bischoff et $\mathrm{al}^{33}$ attributed to gentamycin sulfate.

While there has been doubt in some circles about the relationship of critical illness polyneuropathy and critical illness myopathy to sepsis, the relationship appears now to be established. In the recent systematic review by Stevens et $\mathrm{al}^{34}$ at Johns Hopkins, USA, 1421 patients were evaluated in 24 studies. Forty-six percent were diagnosed with critical illness neuromuscular abnormalities. These abnormalities are linked to hyperglycemia, the systemic inflammatory response syndrome, sepsis, renal replacement therapy, and catecholamine administration. All are markers of severe sepsis and multiple organ failure.

There have been recent observations on the pathophysiology. Bostock and colleagues, ${ }^{35}$ Institute of Neurology, London, UK, utilized methods testing nerve excitability. They showed that motor axons in critically ill polyneuropathy patients are depolarized by two possible mechanisms: raised extracellular potassium or hypoperfusion. The last mechanism would fit with our theory of disturbances of the microcirculation to peripheral nerve. $^{21}$ Allen et $a l,{ }^{36}$ King's College Hospital, London, UK, utilized several electrophysiological techniques, and attributed a reduced muscle excitation threshold and conduction velocity to an acquired channelopathy. Again, I wonder if these changes could be explained by a disturbance of microcirculation to muscle. 


\section{Spin-offs}

There have been several important spin-offs. I will mention two.

We had inferred that difficulty in weaning from the ventilator in critically ill patients was often due to the axonal degeneration of the peripheral nerves involved in respiration. At that time the techniques of phrenic nerve conduction and needle EMG of the diaphragm were rarely used. We therefore embarked on a series of investigations which developed the techniques and established them as valuable not only in the ICU but in other clinical settings. A wide variety of neuromuscular disorders were investigated. The book, Neurology of Breathing, by Bolton, Chen, Wijdicks, and Zifko, is an exposition of these investigations. ${ }^{37}$

In a broader perspective, Bryan Young and I recognized that in the Victoria Hospital 30-bed ICU, in addition to the primary neurological and neurosurgical admissions, such as head injury and stroke, there were the medical and surgical admissions, such as severe pneumonia or multiple trauma, that were often complicated by nervous system disease. Both groups required neurological and neurosurgical expertise. Hence, in 1991, we established the Canadian Neurocritical Care Group ${ }^{38}$, which has, often under the direction of Jeanne Teitelbaum, met and held successful yearly courses at the Canadian Neurological Sciences Federation. Over the years colleagues and I organized symposia dealing with various aspects of neurocritical care at national and international meetings. Recently the Canadian Neurocritical Care Group has evolved into the Canadian Neurocritical Care Society ${ }^{39}$, a collaborative effort of Canadian neurologists and neurosurgeons, and intensivists, the Canadian Critical Care Society. These arrangements were spearheaded by Draga Jicci, neurologist, and David Zygum, intensivist. It is now possible for doctors to receive full training in Canada as neurointensivists.

\section{ACKNOWLEDGEMENTS}

"I realize I couldn't have done it without the players". Casey Stengel, manager of the New York Yankees.

The "players" are too numerous to list here. Many will be found as co-authors in published abstracts, papers, and books. I must mention Bill Sibbald and Frank Rutledge, former Directors of our ICU, now deceased. Ms. Betsy Toth, University of Western Ontario, my former secretary, prepared almost all the manuscripts. Ms. Holly Shea, Queen's University, prepared the present manuscript.

\section{REFERENCES}

1. Bolton CF. The discovery of critical illness polyneuropathy. Eur $\mathrm{J}$ Anaesthesiol Suppl. 2008;25 Suppl 42:66-7.

2. Bolton CF, Young GB, Zochodne DW. The neurological complications of sepsis. Ann Neurol. 1993;33:94-100.

3. Kress JP, Pohlman AS, O'Connor ME, Hall JB. Daily interruption of sedative infusions in critically ill patients undergoing mechanical ventilation. N Engl J Med. 2000;342:1471-7.

4. De Jonghe B, Cook D, Sharshar T, Lefaucheur JP, Carlet J, Outin H. Acquired neuromuscular disorders in critically ill patients: a systemic review; groupe de Reflexion et d'Etude sur les Neuromyopathies En Reanimation. Intensive Care Med. 1998; 24:1242-50.

5. Bolton CF, Gilbert JJ, Hahn AF, Sibbald WJ. Polyneuropathy in critically ill patients. J Neurol Neurosurg Psychiatry. 1984;47: 1223-31.
6. Bolton CF, Laverty DA, Brown JD, Witt NJ, Hahn AF, Sibbald WJ. Critically ill polyneuropathy: electrophysiological studies and differentiation from Guillain-Barré syndrome. J Neurol Neurosurg Psychiatry. 1986;49:563-73.

7. Feasby TE, Gilbert JJ, Brown WF, Bolton CF, Hahn AF, Koopman $\mathrm{WF}$, et al. An acute axonal form of Guillain-Barré polyneuropathy. Brain. 1986;109:1115-26.

8. Bolton CF. Electrophysiologic studies of critically ill patients. Muscle Nerve. 1987;10:129-35.

9. Dyck PJ, Karnes J, Lais A, Lofgren EP, Stevens JC. Pathologic alterations of the peripheral nervous system of humans. In: Dyck PJ, Thomas PK, Lambert EH, Bunge R, editors. Peripheral neuropathy, Volume 1. 2nd ed. Philadelphia and London: Saunders WB; 1984. p.760-870.

10. Zochodne DW, Bolton CF, Wells GA, Gilbert JJ, Hahn AF, Brown JD, et al. Critical illness polyneuropathy. A complication of sepsis and multiple organ failure. Brain. 1987;110:819-41.

11. Witt NJ, Zochodne DW, Bolton CF, Grand'Maison F, Wells G, Young GB, et al. Peripheral nerve function in sepsis and multiple organ failure. Chest. 1991;99:176-84.

12. Bolton CF, Baltzan MA, Baltzman RB. Effects of renal transplantation on uremic neuropathy. A clinical and electrophysiologic study. N Engl J Med. 1971;284(21):1170-5.

13. Bolton CF, Sawa GM, Carter K. The effects of temperature on human compound action potentials. J Neurol Neurosurg Psyhiatry. 1981;44:407-13.

14. Bolton CF, Carter KM. Human sensory nerve compound action potential amplitude: variation with sex and finger circumference. J Neurol Neurosurg Psychiatry. 1980;43:925-8.

15. Jackson AC, Gilbert JJ, Young GB, Bolton CF. The encephalopathy of sepsis. Can J Neurol Sci. 1985;12:303-7.

16. Young GB, Bolton CF, Austin TW, Archibald YM, Gonder J, Wells GA. The encephalopathy associated with septic illness. Clin Invest Med. 1990;13:297-304.

17. Bolton CF, Young GB. Sepsis and septic shock: central and peripheral nervous systems. In: Sibbald WJ, Sprung CL, editors. New horizons: perspectives on sepsis and septic shock. Fullerton: Society of Critical Care Medicine; 1986:157-71.

18. Bolton CF. Evidence of neuromuscular dysfunction in the early stages of the systemic inflammatory response syndrome. Intensive Care Med. 2000;26:1179-80.

19. Zochodne DW, Thompson RT, Driedger AA, Strong MJ, Gravelle $\mathrm{D}$, Bolton CF. Metabolic changes in human muscle denervation: topical 31P NMR spectroscopy studies. Magn Reson Med. 1988; 7:373-83.

20. Bolton CF, Young GB, Zochodne DW. Neurological changes during severe sepsis. Curr Topics Intensive Care. 1994;1:759-73.

21. Bolton CF. Neuromuscular manifestations of critical illness. Muscle Nerve. 2005;32:140-53.

22. Op de Coul AA, Verheul GA, Leyten AC, Schellens RL, Teepen JL. Critical illness polyneuromyopathy after artificial respiration. Clin Neurol Neurosurg. 1991;93:27-33.

23. Lacomis D, Zochodne DW, Bird SJ. Critical illness myopathy. Muscle Nerve. 2000;23:1785-8.

24. Rich MM, Teener JW, Raps EC, Schotland DL, Bird SJ. Muscle is electrically inexcitable in acute quadriplegic myopathy. Neurology. 1996;46:731-6.

25. Zochodne DW, Ramsay DA, Saly V, Shelley S, Moffat S. Acute necrotizing myopathy of intensive care: electrophysiological studies. Muscle Nerve. 1994;17:285-92.

26. Latronico N, Fenzi F, Recupero D, Guarneri B, Tomelleri G, Tonin P, et al. Critical illness myopathy and neuropathy. Lancet. 1996; 347:1579-82.

27. Dubois RJ. Free lance of science: Louis Pasteur. Boston: Little Brown and Co.; 1950

28. Brock TD. Robert Koch: a life in medicine. Madison, WI: Science Tech Publishers; 1988.

29. Osler W. The principles and practice of medicine. New York: D Appleton; 1892.

30. Erbsloh F. Polyneuritic pathological conditions in internal medicine. Munch Med Wochenschr. 1955;97:753-6. 
31. Mertens HG. Disseminated neuropathy following coma. On the differentation of so-called toxic polyneuropathy. Nerve-narzt. 1961;32:71-9.

32. Henderson B, Koepke GH, Feller I. Peripheral neuropathy among patients with burns. Arch Phys Med Rehabil. 1971;52:149-51.

33. Bischoff A, Meier C, Roth F. Gentamicin neurotoxicity (polyneuropathy-encephalopathy). Schweiz Med Wochenschr. 1977;107:3-8.

34. Stevens RD, Dowdy DW, Michaels RK, Mendez-Tellez PA, Pronovost PJ, Needham DM. Neuromuscular dysfunction acquired in critical illness: a systematic review. Intensive Care Med. 2007;33:1876-91.
35. Z'Graggen WJ, Lin CS, Howard RS, Beale RJ, Bostock H. Nerve excitability changes in critical illness polyneuropathy. Brain. 2006;129:2461-70.

36. Allen DC, Arunachalam R, Mills KR. Critical illness myopathy: further evidence from muscle-fiber excitability studies of an acquired channelopathy. Muscle Nerve. 2008;37:14-22.

37. Bolton CF, Chen R, Wijdicks EFM, Zifko UA. Neurology of breathing. Philadelphia: Butterworth Heinemann \& Elsevier; 2004.

38. Notes and announcements. Can J Neurol Sci. 18;110:1991.

39. Thenayan EA, Bolton CF, Jichici D, Savard M, Teitelbaum J, Young $B$, et al. Neurocritical care in Canada: evolving streams in a new discipline. Can J Neurol Sci. 2008;35:405-8. 